\title{
A cidadania europeia na escola: complementando o currículo
}

\author{
Filipe Piedade ${ }^{1}$ \\ ORCID: 0000-0001-6490-5472 \\ Norberto Ribeiro ${ }^{1}$ \\ ORCID: 0000-0001-7581-7902 \\ Carla Malafaia ${ }^{1}$ \\ ORCID: 0000-0001-5490-1187 \\ Manuel Loff ${ }^{1}$ \\ ORCID: 0000-0001-5958-650X \\ Isabel Menezes ${ }^{1}$ \\ ORCID: 0000-0001-9063-3773 \\ Tiago Neves ${ }^{1}$ \\ ORCID: 0000-0002-4309-5906
}

\section{Resumo}

0 projeto de criação de uma cidadania europeia comum pede aos sistemas educativos dos vários estados-membros da União Europeia (UE) que contribuam para a formação de cidadãos europeus críticos/as e ativos/as relativamente ao objetivo de prossecução e aperfeiçoamento do projeto europeu. Em Portugal, estudos anteriores ao nível do ensino secundário identificaram sérias lacunas, tanto nos currículos como nos manuais escolares de algumas disciplinas, nas abordagens pedagógicas sugeridas para o processo de ensino/ aprendizagem acerca dessa dimensão europeia. Neste artigo, procurou perceber-se que tipos de atividades extra e co-curriculares as escolas têm vindo a dinamizar no sentido de complementar essas lacunas. Para tal, foram entrevistados/as 16 professores/as de 4 escolas do ensino secundário português. Os seus discursos permitiram identificar vários tipos de atividades extra e co-curriculares que têm vindo a ser dinamizadas pelas escolas para aumentarem o conhecimento e o nível de reflexividade dos/as estudantes sobre a UE. A análise desses relatos permitiu ainda identifıcar potencialidades e limitações inerentes ao desenvolvimento destas atividades, assim como produzir algumas recomendações para que as escolas possam dar uma contribuição mais eficaz ao projeto de consolidação de uma cidadania europeia ativa e crítica.

\section{Palavras-chave}

Cidadania europeia - Atividades co-curriculares - Atividades extracurriculares - Professores.

1- Universidade do Porto, Porto, Portugal. Contatos: fpiedade@fpce.up.pt; norberto@fpce.up.pt; carlamalafaia@fpce.up.pt; mloff@letras.up.pt; imenezes@fpce.up.pt; tiago@fpce.up.pt 


\section{European citizenship in school: supplementing the curriculum}

\section{Abstract}

The project of creating a common European citizenship requires that the educational systems from the different member-states of the European Union (EU) contribute to the education of European citizens that are critical and active regarding the objective of continuing and perfecting the European project. In Portugal, previous studies of upper secondary education have shown serious shortcomings, both in the curricula and the textbooks of several subjects, in the pedagogical approaches suggested for the process of teaching/learning about this European dimension. In this article, we have tried to find out which kind of extra and co-curricular activities the schools have been organizing to fill the previously mentioned shortcomings. To that end, we have interviewed 16 teachers from 4 different schools of the Portuguese upper secondary educational system. Their accounts have allowed us to identify several kinds of extra and co-curricular activities that have been implemented by their schools in order to increase their students' level of knowledge and reflexiveness regarding the EU. The analysis of these accounts has also allowed us to identify both the potential and limitations involved in developing these activities and to make some general recommendations towards improving the conditions for the schools to give a more efficient contribution to the objective of consolidating a active and critical European citizenship.

\section{Keywords}

European citizenship - Co-curricular activities - Extracurricular activities - Teachers.

\section{Introdução}

Mais de duas décadas após a sua introdução legal, a consolidação de uma cidadania europeia continua a deparar-se com dificuldades como a incapacidade da União Europeia (UE) para criar uma identidade cívica comum (CHRYSSOCHOOU, 2006) entre as populações dos seus estados-membros. Confrontadas com essas dificuldades, as instituições europeias têm vindo a apelar aos Estados para que aumentem "o diálogo sobre a UE nas nossas escolas, associações e nos espaços públicos” (PARLAMENTO EUROPEU, 2016, p. 13). Por outro lado, sendo a cidadania ativa uma das principais premissas das democracias representativas, a UE, enquanto construção que se assume como defensora dos valores democráticos, não poderia dispensar formas de participação política - tais como o voto que caracterizam os sistemas eleitorais democráticos. Contudo, a fluidez atual do conceito de cidadania leva a que "as crenças sobre o que implica a cidadania ativa sejam bastante divergentes” (LAWSON, 2001, p. 166), com as gerações mais jovens, em particular, a alargarem significativamente o leque de formas e canais de participação (NORRIS, 2002). 
Mesmo considerando que a escola é “apenas uma entre muitas instituições e organizações" (BEANE, 1990, p. 54) responsáveis "pelo desenvolvimento de um modo de vida democrático" (BEANE, 1990, p. 54), a verdade é que os conteúdos e conhecimentos que ela procura transmitir acabam por atribuir um papel central à educação nas questões associadas à cidadania participativa (FONSECA, 2014). Ao reconhecer essa centralidade, a UE tem vindo a procurar que "a ideia da Europa seja aceita e amplamente incorporada nos currículos escolares e nos manuais escolares” (NÓVOA; LAW, 2002, p. 62), mas continua a enfrentar dificuldades para se afirmar "nas escolas, faculdades e outras instituições educativas e nos corações e nas mentes dos seus alunos e estudantes” (RYBA, 2000, p. 259).

Perante essas dificuldades, algumas investigações têm vindo a reforçar a ideia de que, ao "procurar educar para a cidadania europeia, os currículos nacionais deveriam adotar uma abordagem multifacetada (e crítica) relativamente ao ensino sobre a Europa" (KEATING, 2014, p. 59). Esse tipo de abordagem pedagógica implicaria, provavelmente, uma remodelação dos sistemas educativos europeus no sentido da implementação de um novo paradigma educativo que permitisse contornar formas de "domesticação da cidadania" (BIESTA, 2011, p. 44) que promovem a mera "(re)produção do cidadão ativo competente” (BIESTA, 2011, p. 44). Pelo contrário, esse novo modelo educativo permitiria uma educação mais democrática, baseada na criatividade e no estímulo de "uma verdadeira reflexão e ação sobre a realidade” (FREIRE, 2000, p. 84). Apesar dessas recomendações, aquilo a que se tem assistido é que:

[...] a maior parte dos acordos internacionais e dos programas da UE na contemporaneidade se focam em estratégias de formação baseadas nas competências, desenhadas para forjar todos os estudantes (tanto nativos quanto emigrantes) no sentido da cidadania europeia pela via de um mercado de trabalho cada vez mais sem fronteiras e intra-UE. (MITCHELL, 2006, p. 396).

Ou seja, as políticas adotadas pela UE, incluindo as relativas à sua tentativa de consolidação de uma cidadania comum através da educação, parecem surgir integradas numa corrente neoliberal na qual as instituições europeias se deixaram arrastar (HERMANN, 2007).

Essas circunstâncias vêm levando alguns autores a sublinhar a urgência de retomar "o potencial democrático da educação" (GIROUX, 2016, p. 298) e de promover salas de aula verdadeiramente democráticas nas quais se valorizem "coisas como a voz do aluno, um currículo integrador, disciplinas centradas na resolução de problemas, atividades colaborativas, recursos multiculturais e avaliações reflexivas” (BEANE, 2017, p. 1050). Para que essa democratização aconteça haverá, contudo, que reconhecer que o próprio currículo "é resultado das disputas pelo poder, apresentando modos de pensar e de produzir o mundo, [e] construindo hegemonias" (REZENDE; SILVA; DE LELIS, 2014, p. 1003) e adotar uma "estrutura curricular crítico-emancipatória" (AGUIAR, 2017, p. 1098) que se centre na capacidade dos/as estudantes (des)construírem reflexivamente a realidade social que os/as rodeia (CHIARO; AQUINO, 2017).

Acresce que esse novo enquadramento curricular deveria ter em atenção que o currículo passa por um processo de reconstrução durante a sua implementação na prática diária de professores/as e alunos/as. Embora, em geral, as atuais diretrizes curriculares reconheçam essa ação dos/as professores/as como desejável, vários estudos vêm denunciando que: 
[...] os conceitos de autonomia, participação, comunidade, projeto e descentralização, entre outros, se encontram preferencialmente na discursividade dos normativos e documentos de orientação política da administração central, e não nas práticas dos professores. (PACHECO; PEREIRA, 2007, p. 393).

Nesse sentido, "conclui-se que o exercício da autonomia na (re)construção do currículo no cotidiano escolar constitui-se em um jogo de força e de poder entre as esferas legais, administrativas e pedagógicas" (SCHIABEL; FELICIO, 2018, p. 831), no qual, recorrentemente, os/as professores/as saem derrotados/as pelos "constrangimentos normativos, impostos pelo poder central, nomeadamente nas questões relativas à avaliação externa e interna, bem como à organização das próprias escolas" (MENDES, 2013, p. 242).

Também no que concerne às questões europeias, verifica-se que, em Portugal, "a identidade e a autonomia curriculares da escola são aspectos valorizados nos discursos políticos, mas facilmente contraditados pelas práticas escolares" (PACHECO; PEREIRA, 2007, p. 394). Aliás, a dimensão europeia tem vindo, na verdade, a contribuir "para a legitimação de práticas escolares uniformes, tornando o currículo num facto" (PEREIRA, 2007, p. 394). Essa rigidez curricular tende a ignorar que "para aumentar o conhecimento dos jovens sobre a UE, pode ser que os jovens cidadãos não precisem de mais oportunidades para aprenderem sobre a Europa, mas sim de melhores oportunidades para o fazer" (KEATING, 2014, p. 179).

Perante esse cenário, assumem especial importância atividades disponibilizadas pelas escolas que tenham potencial pedagógico e que transcendam as imposições curriculares. Efetivamente, alguns estudos demonstram existirem evidências sobre os efeitos positivos das atividades extracurriculares no envolvimento político (MARZANA; MARTA; POZZI, 2012), incluindo a longo prazo (KEATING; JANMAAT, 2016) e na promoção de competências interculturais, democráticas e de cidadania ativa (KESER; AKAR; YILDIRIM, 2011). Essas evidências parecem encontrar correspondência na opinião dos/as professores/as, que também veem a participação nesse tipo de atividades como positiva para o desenvolvimento dos/as estudantes e para o seu sucesso acadêmico (KARIYANA; MAPHOSA; MAPURANGA, 2012). Ou seja, não obstante a necessidade de se ter em atenção a qualidade das experiências de participação nessas atividades (FERREIRA; AZEVED0; MENEZES, 2012), a generalidade das investigações realizadas nessa área parece confirmar a existência de efeitos positivos para o desenvolvimento das gerações mais jovens (FREDRICKS et al., 2002; FREDRICKS; ECCLES, 2005; MEHMOOD et al., 2012) e para o seu nível de conhecimentos acerca de questões europeias (SAVVIDES, 2008; CAETANO et al., 2016).

Apesar da proliferação de estudos empíricos nessa área, teoricamente verificase ainda, contudo, uma confusão conceitual entre atividades extracurriculares e cocurriculares. Assim sendo, e partindo da definição de atividade extracurricular avançada por Bartkus et al. (2012), para os efeitos deste estudo consideraremos como atividade co-curricular uma atividade acadêmica promovida ou apoiada pelo/a professor/a de uma determinada disciplina e que, embora não seja especificamente sugerida nem pelo programa curricular nem pelo manual escolar adotado nessa mesma disciplina, ocorre dentro do 
horário escolar previsto para a mesma, podendo ser desenvolvida dentro ou fora da sala de aula. Embora essa atividade não seja quantitativamente avaliada pelo/a professor/a, os conteúdos da participação e eventuais registros da mesma são habitualmente considerados na avaliação individual dos/as estudantes.

Tomamos ainda como ponto de partida deste artigo resultados da análise de manuais das disciplinas de História $\mathrm{A}^{2}$ e de Inglês como Língua Estrangeira (ILE) do ensino secundário português. Esses resultados são fruto da nossa pesquisa anterior e revelam que essas ferramentas pedagógicas apresentam lacunas significativas relativamente às suas sugestões para a abordagem de temas relacionados com a UE. Com efeito, apesar de apresentarem temas relacionados com a integração europeia com um considerável nível de detalhe e complexidade, revelam uma preocupante incapacidade de inspirar uma abordagem crítica e promotora de controvérsia acerca desses mesmos temas. Pelo contrário, promovem nos/as estudantes uma visão normativa do seu estatuto de cidadãos europeus, baseada essencialmente em uma definição jurídica de direitos e deveres (PIEDADE et al., 2018).

Neste trabalho, alargaremos o conhecimento acerca da abordagem de temas europeus no ensino secundário português aos tipos de atividades extra e co-curriculares que vêm sendo dinamizados pelas escolas no sentido de aumentar o conhecimento e o nível de reflexividade dos/as estudantes relativamente à UE e ao seu projeto de consolidação de uma cidadania europeia comum.

\section{Metodologia}

Tendo em consideração que “a principal forma de um/a investigador/a investigar uma organização, instituição ou processo educativo é através da experiência dos indivíduos, dos 'outros' que compõem a organização ou que desenvolvem o processo" (SEIDMAN, 2006, p. 10), analisaremos os discursos de professores/as das disciplinas de História, ILE e Área de Integração (AI) de quatro escolas do ensino secundário português (cf. Tabela 1).

Tabela 1 - Professores/as entrevistados/as por disciplina

\begin{tabular}{|c|c|c|c|c|}
\hline Escola/Disciplina & História & ILE & $\mathrm{Al}$ & Total \\
\hline Escola\#1 & 0 & 2 & $2^{*}$ & 4 \\
\hline Escola\#2 & 2 & 1 & 1 & 4 \\
\hline Escola\#3 & $2^{* *}$ & 2 & 0 & 4 \\
\hline Escola\#4 & 1 & 2 & 1 & 4 \\
\hline Total & 5 & 7 & 4 & 16 \\
\hline
\end{tabular}

\footnotetext{
*Um/a dos/as participantes leciona também História

${ }^{* *}$ Os/as dois participantes lecionam também Área de Integração Fonte: dados da pesquisa.
}

2- A disciplina História A é obrigatória para estudantes do ensino secundário português $\left(10^{\circ}, 11^{\circ}\right.$ e $12^{\circ}$ anos) que estejam inscritos/as no Curso de Línguas e Humanidades. Os/as estudantes inscritos/as no Curso de Ciências Socioeconômicas podem optar por escolher a disciplina História $\mathrm{B}\left(10^{\circ}\right.$ e $11^{\circ}$ anos $)$. 
Este estudo inclui escolas do ensino profissional (Escola\#1) e do ensino regular (Escolas \#2, \#3 e \#4), sendo que a sua seleção foi feita tendo como critério a representação de contextos socioeconômicos de baixos rendimentos (Escolas \#1 e \#3) e de rendimentos médios/altos (Escolas \#2 e \#4).

A seleção de professores/as corresponde às duas disciplinas - História e ILE estudadas no artigo sobre a análise de manuais escolares anteriormente referido (PIEDADE et al., 2018), às quais se juntaram professores/as da disciplina de AI no sentido de obter as perspectivas de docentes mais diretamente envolvidos/as no ensino profissional, já que a disciplina que lecionam é exclusiva dos planos de estudos de cursos profissionais. 0 anonimato dos/as professores/as participantes foi garantido através da utilização de nomes fictícios.

As opiniões dos/as participantes foram recolhidas através da realização de entrevistas semiestruturadas. As entrevistas foram realizadas entre novembro de 2016 e junho de 2017 no âmbito do projeto de investigação europeu CATCH-EyoU - Constructing AcTive CitizensHip with European Youth: Policies, Practices, Challenges and Solutions (European Union Horizon 2020, Grant Agreement N. 649538). A condução das entrevistas foi feita com recurso a um roteiro desenvolvido especificamente para o efeito e que procurava obter as perspectivas dos/as participantes relativamente: i) às políticas educativas em Portugal; ii) ao papel da escola na vida dos/as estudantes; iii) às experiências, dentro e fora da escola, que os/as professores/as consideram ser importantes para o desenvolvimento dos/ as jovens; iv) ao uso dos manuais escolares e de outras ferramentas pedagógicas; v) ao papel dos/as jovens no contexto escolar e social; e vi) a como obter recomendações para as autoridades nacionais e europeias e sugestões para futuras investigações nesta área.

Uma das perguntas incluídas no roteiro questionava diretamente os/as professores/ as se consideravam que as suas escolas tinham "promovido a conscientização social, cívica e política dos estudantes tanto a nível local como europeu". No seguimento da resposta a essa questão, perguntava-se especificamente se alguma vez tinham tido "contato direto com projetos ou iniciativas que tivessem esses objetivos", pedindo-se, de seguida, alguns exemplos de iniciativas que tivessem "decorrido dentro e fora das aulas na sua escola". Os discursos produzidos em resposta a essas questões constituem o foco das seções seguintes deste artigo. Contudo, dada a flexibilidade do roteiro utilizado, na maior parte dos casos os/as professores/as entrevistados/as foram identificando esse tipo de iniciativas ao longo de toda a entrevista. Assim sendo, as gravações áudio das entrevistas foram integralmente transcritas e posteriormente sujeitas a uma análise de conteúdo (JOFFE; YARDLEY, 2004) que procurou identificar referências a atividades desenvolvidas em contexto escolar (dentro e fora da sala de aula) relacionadas com assuntos europeus.

\section{Atividades co-curriculares}

Boa parte dos/as professores/as do ensino regular sublinha que os/as estudantes continuam a perceber o seu processo de aprendizagem como estando baseado na memorização e não na reflexão dos conteúdos curriculares. Na opinião de alguns professores/as, apesar de um aumento no número de projetos escolares que procuram 
demonstrar aos estudantes a aplicabilidade dos seus conhecimentos, faltam ainda mais iniciativas que reforcem essa ligação entre a teoria e a prática. A seguinte opinião é representativa dessas críticas:

A verdade é que eles aprendem os conteúdos curriculares nas disciplinas de História e Geografia, mas por vezes não lhes dão significado social e político. Muitos deles entendem que aquilo é para decorar, para estudar e debitar no teste. E depois faltam projetos - ou, pelo menos, faltaram durante muito tempo - que concretizem essas aprendizagens, que lhes permitam entrar em contacto com o que é ser cidadão europeu. (Elsa, História, escola\#2).

Contudo, em geral, a maioria dos/as entrevistados/as parece acreditar que os/as professores/as têm vindo a fazer um esforço no sentido de aumentar a reflexividade dos/ as estudantes sobre os temas que vão sendo abordados nas suas aulas. Com efeito, uma boa parte dos/as participantes neste estudo referiram tentar promover debates sobre esses mesmos assuntos.

Este paradigma do professor que faz testes, do professor que quer a matéria decorada, acho que está a acabar. Se já não acabou. [...] É mais promover o debate. Ver os assuntos que lhes interessam. (Sónia, AI, escola\# 1).

Tal parece, contudo, ser mais viável no ensino profissional do que no ensino regular, já que o primeiro parece beneficiar de uma maior flexibilidade curricular que dá aos professores tempo e autonomia suficientes para a realização de atividades pedagógicas mais interativas:

No meu caso, eu costumo aproveitar para debates e temas... lanço um tema e depois divido sempre a turma em dois, o lado do "sim" e o lado do "não", e depois na outra aula troco-os que é para eles... e estão todos ali a ter uma perspetiva de um lado e a ter uma perspetiva do outro. (José, AI, escola\# 1).

No que se refere a questões relacionadas com a UE, esse tipo de atividades poderia passar pelo questionamento do futuro da própria União.

Será que vale a pena continuarmos, e sermos a Europa unida? E será que somos assim tão unidos? Nem que fosse assim este tipo de perguntas. 0 professor também tinha aqui que pensar bem no assunto. [...] Aumentar-lhes a cultura geral, ao menos. Nem que fosse por cultura geral. Ao menos. Se isso os ia fazer mais participativos? Não sei. (Helena, ILE, escola\#3).

$\mathrm{Ou}$ seja, alguns professores/as parecem dispostos a pôr em prática atividades pedagógicas que estimulem um posicionamento crítico dos/as estudantes relativamente ao caminho percorrido pela UE e ao futuro da mesma, embora vários/as entrevistados/ as tenham reconhecido que o desenvolvimento desse tipo de atividades "depende muito do perfil do professor” (Sónia, AI, escola\#1). A um nível mais institucional, alguns 
professores/as sublinharam ainda a importância de algumas iniciativas europeias na área da educação, tais como o programa eTwining:

0 eTwinning é uma plataforma onde são desenvolvidos projetos com outras escolas europeias, de vários países. Portanto, o professor coloca lá o seu perfil, diz o que é que está interessado em fazer e depois surgem parceiros que dizem "eu quero fazer..." e, então, surge esse projeto entre as várias escolas que podem ser em mais do que um país. (Joana, ILE, escola\#4).

Mesmo fora da sala de aula, mas ainda no âmbito disciplinar, vários/as professores/ as identificaram a realização de debates acerca de questões políticas, nacionais e europeias. $\mathrm{Na}$ escola\#4, por exemplo, organiza-se, anualmente, um ciclo de debates que, na edição recordada pela professora Maria, se dedicou especificamente ao tema da cidadania europeia e que, em edições anteriores, serviu também de espaço para uma reflexão política dos/as estudantes partindo do visionamento de filmes sobre várias temáticas:

Assim de repente, estou-me a lembrar da Filosofia, o ano passado e há dois anos cujos temas dos debates tinham mesmo a ver com a cidadania europeia, com a questão das exclusões, a questão do terrorismo também na Europa. Portanto, houve debates nesse sentido. Questões europeias... também se passou o ciclo de cinema, [...] Praticamente todas as disciplinas têm atividades dentro desse género. (Maria, História, escola\#4).

Outra professora da mesma escola reforçou a ideia de proliferação de iniciativas cocurriculares desse gênero no âmbito de várias disciplinas, chamando, contudo, a atenção para um problema relacionado com a falta de informação sobre o desenvolvimento das mesmas dentro de escolas de grande dimensão:

Que é um grande problema da escola, ser muito grande e de haver muitas iniciativas, a páginas tantas, de algumas, quase só sabemos em cima da hora e outras não ficamos a saber e outras lembramo-nos vagamente, porque são muitas. (Teresa, ILE, escola\#4).

A confirmar esse dinamismo de algumas escolas na organização de atividades com potencial na promoção da reflexão política dos/as jovens, assim como o interesse e motivação de muitos/as estudantes para participarem nas mesmas, surge o relato da professora Elsa acerca da extensão de um debate sobre questões políticas para além do horário escolar originalmente previsto:

No ano passado fizemos um debate - foi tão engraçado! -, "os jovens e a Europa" e convidámos os presidentes das Jotas ${ }^{3}$ famalicenses e lá vieram eles. Ao fim de 90 minutos era suposto aquilo ter acabado [...] eram $18 \mathrm{~h} 15$ e a atividade ainda estava a decorrer e com muita gente no auditório. Três horas, 90 + 90 [minutos], os jovens a discutir política. (Elsa, História, escola\#2).

3- 0 termo "Jotas" é utilizado para designar as Juventudes Partidárias que fazem parte de vários partidos políticos portugueses. 
Para além de, segundo os relatos dos/as professores/as entrevistados/as, a promoção de debates sobre questões políticas, tanto nacionais como europeias, ser uma prática habitual nas várias escolas aqui representadas, e das restantes iniciativas dinamizadas no âmbito de várias disciplinas do ensino secundário, a escola\#3 aproveita ainda uma parceria com a Câmara Municipal e com a Universidade para organizar uma iniciativa intitulada Aulas sem Fronteiras. Nessa iniciativa:

Vêm cá alunos estrangeiros que estão na Universidade. São alunos que estão a estudar no Porto e vêm cá a uma aula específica e dão uma aula na sua língua. [...] E trazem qualquer coisa, à escolha deles. Eu já assisti uma vez a um que veio de Espanha e falou sobre Espanha. Sobre a vida dele. Trouxe uma apresentação. (Heloísa, História, escola\#3).

Outra professora dessa escola sublinhou a importância dessa iniciativa no sentido de aproximar os/as estudantes portugueses/as do resto da Europa, promovendo, simultaneamente, uma visão multicultural do espaço europeu:

Aí sim, eles [estudantes] começam a ver como na Europa temos diferenças. Então quando eles apanham alunos de Inglaterra ou de França, depois vamos apanhar da Grécia... este que cá veio era de um país de leste que agora não me recordo o nome. [...] Completamente diferentes. E aí eles aperceberam-se das diferenças, e [que] estamos na Europa. (Sara, ILE, escola\#3).

Infelizmente, sendo essa essencialmente uma iniciativa dos/as professores/as de línguas dessa escola, e apesar da intenção de organizar esse tipo de atividades anualmente, nem sempre a disponibilidade dos/as alunos Erasmus permite que tal aconteça, como se pode verificar no seguinte relato: "por exemplo, eu este ano inscrevi-me e estava à espera de pessoas. Preparei os alunos para isso e eles, depois, não apareceram. Nem sempre funciona. Às vezes falha. Mas, no geral, funciona” (Sara, ILE, escola\#3).

Em suma, apesar das constantes denúncias feitas pelos/as professores/as do ensino regular sobre a falta de tempo para aprofundarem algumas das iniciativas anteriormente descritas, vários/as deles/as parecem estar a conseguir complementar os conhecimentos programáticos previstos sobre assuntos europeus. Ainda assim, e dada a excessiva dimensão dos currículos das várias disciplinas do ensino regular, os relatos dos/as professores/as das três escolas do ensino regular demonstraram que uma boa parte do envolvimento e reflexão dos/as estudantes relativamente a essas questões se faz em regime extracurricular.

\section{Atividades extracurriculares}

Como já foi referido, os/as professores/as inseridos no ensino profissional reconhecem dispor de mais tempo e autonomia do que os seus colegas do ensino regular para abordar questões europeias durante as aulas. Talvez essa seja uma explicação parcial para o fato de os/as entrevistados/as da escola\# 1 não terem conseguido identificar atividades extracurriculares sobre temas europeus que sejam dinamizadas pela escola em que estão inseridos/as. Os/as professores/as do ensino profissional entrevistados/as identificaram também outras dificuldades com as quais se deparam nas suas tentativas para promover 
esse tipo de atividades fora do contexto escolar. 0 seguinte relato é um bom exemplo dessas dificuldades:

No passado tentei ir ao Parlamento e são assuntos que...é muito complicado. Ou porque há um debate lá, há sempre um qualquer assunto complicado [...]. Eu já nem falo no [Parlamento] Europeu, não é. Mas pelo menos o nacional. [...] Mas, levar os jovens a sítios e não ser sempre dentro da sala que estejam os assuntos a ser debatidos, mas estar na prática um dia. (José, AI, escola\#1).

Aliás, as dificuldades mencionadas pelo professor José parecem ser partilhadas pela maioria dos/as seus colegas, tanto do ensino profissional como do ensino regular, e enquadradas numa crítica mais geral de falta de ligação entre as escolas e a classe política, tanto nacional como europeia (PIEDADE et al., 2020).

Isto não significa que não tenham sido identificadas atividades realizadas pelos/as alunos/as fora da escola\#1, mas essas estão, geralmente, mais associadas ao desenvolvimento prático das competências específicas do curso em que se encontram e "não ligadas ainda à temática europeia" (Sónia, AI, escola\#1). Curiosamente, a professora Mafalda, ao identificar as visitas de estudo ao estrangeiro como uma das atividades extracurriculares que melhor expõem os/as estudantes a questões europeias, identificou a existência de uma verba atribuída a cada aluno/a do ensino profissional para deslocações, o que, em teoria, deveria facilitar o desenvolvimento desse tipo de iniciativas na escola\# 1:

Mafalda: Olhe, há pouco tempo tivemos duas saídas, uma para Barcelona e outra para Londres, em que eles vão ver as instituições... fazemos algumas coisas dessas.

Moderador/a: Como é que se consegue fazer isso numa escola?

Mafalda: Quando envolve cursos profissionais, há uma verba destinada a saídas e, portanto, canalizamos o dinheiro para isso. Depois, muitas vezes os miúdos também comparticipam com algum, não muito, não se pode pedir muito dinheiro. Normalmente, os professores pagam a sua viagem e tudo o resto na íntegra, para sobrar mais para eles (Mafalda, História, escola\#3).

Considerando que a maioria dos/as entrevistados/as sublinharam a importância desse tipo de atividades na aproximação entre as gerações mais jovens e a UE, a ausência de relatos sobre a realização de visitas de estudos a outros países da UE por parte dos/ as entrevistados/as na escola\# 1 surge como particularmente preocupante. A explicação para a inexistência desses relatos poderá estar, eventualmente, relacionada com a falta de memória dos/as professores/as entrevistados/as na escola\# 1 relativamente à realização dessas visitas de estudo pelo/as estudantes da sua escola, ou poderá tratar-se de uma questão estrutural, socialmente mais profunda, na qual as circunstâncias socioeconômicas podem estar a limitar o acesso de alguns estudantes a esse tipo de atividades.

Acho muito importante. Repare, eles lembram-se de tudo - não será tudo, tudo, mas lembram-se mais depressa do que viram. Lembram-se que vimos o Parlamento em Londres, que estava ali à beira do Big Ben. E eles recordam-se perfeitamente. Muito mais do que quando se diz que os ingleses têm o Parlamento... (Mafalda, História, escola\#3). 
0 fato de os discursos dos/as professores/as entrevistados/as na escola\#2 indicarem que a organização de visitas de estudo a vários países europeus serem recorrentes nessa escola poderá indiciar que a segunda das razões avançadas anteriormente é mais plausível.

Fomos com um grupo de 50 alunos [a Roma], mas aqui a questão monetária coloca-se. Apesar de poder ser pago a prestações, não deixa de ser cara uma viagem destas, 600€. [...] Isso foi das mais enriquecedoras e sentidas experiências. Porque a moeda é a mesma, porque tudo é igual, a entrada no aeroporto só com o cartão de cidadão. Isso é a tal realidade que é sentida. Eu acho que esse tipo de visitas tem um impacto muito grande, porque aí é mesmo o confronto com aquela realidade. (Júlia, História, escola\#2).

Este último relato levanta a importante questão do esforço financeiro para a participação dos/as estudantes neste tipo de atividades. Já que a escola\#2 é uma das duas escolas que representa um contexto socioeconômico de rendimento médio/alto, esse elemento poderá ser parte da explicação para a maior ocorrência de atividades extracurriculares dispendiosas para os pais dos/as alunos/as envolvidos/as. Seja como for, essas atividades surgem como concretização de uma genuína convicção dos/as professores/ as entrevistados/as de que o contato dos/as estudantes portugueses/as com as culturas de outros países-membros da UE pode contribuir, decisivamente, para o seu apoio ao projeto europeu e para a sua identificação enquanto cidadãos europeus.

Assim sendo, tanto os responsáveis políticos nacionais como europeus deveriam tomar em consideração as limitações financeiras que foram sendo identificadas pela maioria dos/as entrevistados/as ao desenvolvimento de atividades extracurriculares desse gênero e que têm levado a uma diminuição no número de oportunidades que os/as estudantes portugueses/as têm vindo a ter para contactar com a realidade quotidiana de outras sociedades europeias:

E tendo em conta que nos últimos anos as visitas de estudo diminuíram abruptamente [...] os miúdos dantes, os que eram apoiados pelo escalão $\mathrm{A}$, escalão $\mathrm{B}$, não pagavam visitas, agora é muito mais complicado efetuar visitas de estudo, portanto o número de saídas tem diminuído. (João, AI, escola\#4).

Aliás, esses constrangimentos financeiros poderão estar também na base da explicação para o fato de alguns alunos/as de escolas inseridas em contextos socioeconômicos de rendimento mais baixo, como é o caso da escola\#3, não manifestarem interesse em participar neste tipo de atividades, como se pode verificar no seguinte relato:

A nível da Europa, não. Digo eu: "olhem, vocês gostavam de ir a uma visita de estudo ao Parlamento Europeu”. "Oh! Ver o quê?” "Vocês sabem o que é o Parlamento Europeu? Vocês sabem quem lá está? Vocês sabem quem é que nos representa?” [som de quem não se interessa]. (Helena, ILE, escola\#3).

Em todo o caso, a importância do contato com as pessoas e culturas de outros estadosmembros da UE parece ser uma ideia praticamente consensual entre os entrevistados/ 
as. Segundo a maior parte dos/as professores/as entrevistados/as, essas experiências permitirão uma aproximação entre a UE e os/as jovens portugueses/as, bem como a sua identificação com os valores ético-morais proclamados pela mesma. Esta ideia é aqui reforçada pela professora Júlia:

Os nossos jovens precisam muito de contactar com os povos que fazem parte da UE, nem que seja aqui ao lado, o importante é contactarem com outras realidades, essa diversidade. [...] Ver que somos todos europeus... a questão da unidade na diversidade tem que ser uma aposta, que tem que descer às escolas, e no secundário de um modo mais substancial e mais prático. (Júlia, História, escola\#2).

Tal como acontece no caso do desenvolvimento de algumas iniciativas cocurriculares, também na oferta de atividades extracurriculares se verifica que as escolas se associam, recorrentemente, a outras instituições e associações. Sendo a escola\#2, como veremos, provavelmente, a escola que mais atividades extracurriculares oferece aos seus alunos/as, também nesse caso muitas dessas atividades são organizadas em parceria com uma associação de animação cultural local. É essa parceria que permite aos estudantes dessa escola participarem em atividades extracurriculares que ultrapassam o âmbito disciplinar e que incluem temáticas relacionadas tanto com a dimensão europeia como com as dimensões nacional e local:

Uma das associações aqui em Famalicão, ela interfere em várias áreas. Por exemplo, teatro escolar. [...] 0 projeto Erasmus também está a correr através deles. Eles foram, não sei se foi à República Checa, [...] também foi através dessa associação. Por isso, essa associação tem um protocolo com a nossa escola, mas também tem um protocolo com a Câmara Municipal. (Luísa, ILE, escola\#2).

Os relatos dos/as professores/as entrevistados/as indicam ainda que as três escolas do ensino regular participantes neste estudo têm experiências de participação no programa Parlamento dos Jovens ${ }^{4}$. Assinale-se que a participação na versão europeia dessa iniciativa ${ }^{5}$ parece sofrer também de constrangimentos ao nível das competências linguísticas dos/as estudantes da escola\#3:

É esse. É o Parlamento dos Jovens. 0 nacional. 0 europeu, conheci porque já recebi informação disso mas, na altura, optámos por não... consideramos que não temos aqui um grupo de alunos suficientemente bons em Inglês - dominar a língua. E, na altura, optámos por não participar. (Heloísa, História, escola\#3).

4- 0 programa "Parlamento dos Jovens" é "uma iniciativa da Assembleia da República [Portuguesa], dirigida aos jovens dos $2 .^{\circ}$ e $3 .^{\circ}$ ciclos do ensino básico e do ensino secundário, de escolas do ensino público, privado e cooperativo", que tem como principais objetivos "educar para a cidadania, estimulando o gosto pela participação cívica e política" (cf. http://www.jovens.parlamento.pt/2018_2019/docs/Apresentacao.pdf).

5- 0 "Parlamento Europeu dos Jovens" assume-se como "uma das maiores plataformas europeias para o debate político, encontros interculturais, trabalho de educação de pares e partilha de ideias entre jovens na Europa" (cf. https://pejportugal.com/eyp/). 
Ao contrário, a participação nesse tipo de atividades extracurriculares por parte dos/as alunos/as da escola\#2 parece ser bastante mais comum. $\mathrm{Na}$ realidade, todas as professoras entrevistadas nessa escola destacaram a participação dos/as seus alunos/as nas duas iniciativas anteriormente identificadas, assim como no Clube Europeu ${ }^{6}$ da escola, evidenciando assim um dinamismo extracurricular substancialmente superior ao das restantes escolas participantes neste estudo. Os relatos das duas professoras da escola\# 2 que se seguem são demonstrativos desse mesmo dinamismo:

Através da participação no Parlamento dos Jovens e no Clube Europeu, eles têm um conhecimento mais alargado dessas instituições e de como hão de participar. (Luísa, ILE, escola\#2).

Depois, estas questões do Clube Europeu e do Parlamento Europeu, embora toquem um leque mais pequeno de alunos, dá alguma visibilidade e impacto, e pelo menos suscita alguma curiosidade. (Júlia, História, escola\#2).

Essas iniciativas extracurriculares têm o mérito de, no seu âmbito, dinamizarem uma série de atividades pedagógicas com potencial para levar os/as estudantes a refletirem sobre a UE, como se pode perceber no seguinte excerto:

Por exemplo, grupos de discussão sobre o projeto europeu podem ser criados nos próprios espaços da Antena Informativa ${ }^{7}$, que é outro parceiro importante. Este ano os meus alunos vão participar num flashmob e vão participar também na apresentação à comunidade famalicense de alguma literatura simples sobre o projeto europeu. Outra coisa que eu acho é que, por exemplo, os concursos criados pela representação da UE e pelo Parlamento Europeu são muito importantes. Eu lembro-me de um em que participámos no ano passado, "Apatia ou Participação: visões da democracia”. (Elsa, História, escola\#2).

É importante, contudo, ter em conta que a adesão a esse tipo de iniciativas é relativamente limitada dentro do universo de alunos/as do ensino secundário. Com efeito, uma boa parte dos/as estudantes do ensino secundário em Portugal nunca chega a participar nesse tipo de iniciativas, e, segundo a experiência da professora Elsa, muitos/as dos/as que as experimentam acabam por as abandonar devido ao tempo e empenho que as mesmas requerem:

Muitos deles associam clubes europeus a viagens e intercâmbios e quando percebem que não é só isso, que têm que trabalhar, desistem. Foi o que me aconteceu, que tive uma enchente no início, depois fiquei com o núcleo duro que trabalha comigo. Utilizo alguns documentos pedagógicos fornecidos pela Comissão Europeia ou pelo Parlamento Europeu, este ano o tema

\footnotetext{
6- Os Clubes Europeus são espaços extracurriculares organizados voluntariamente pelas escolas que têm como objetivos "criar entre os seus membros um verdadeiro espírito europeu de cidadania ativa" (cf. http://dge.mec.pt/sites/default/files/DSPE/Clubes_Europeus/linhas_ orientadoras_para_0_funcionamento_dos_clubes_europeus.pdf).

7- A Antena de Informação Europeia assume-se como uma extensão dos Centros de Informação Europe Direct e é um serviço que pretende informar os/as cidadãos europeus sobre as políticas e programas europeus.
} 
são os valores europeus... tem que se trabalhar mais e alguns não conseguem conciliar os estudos e a participação nestas atividades. (Elsa, História, escola\#2).

Segundo o relato da professora Elsa, a dificuldade na conciliação da participação neste tipo de atividades extracurriculares com o tempo requerido para o estudo dos conteúdos curriculares pelos quais os/as estudantes do secundário são avaliados é um forte dissuasor à sua participação nessas iniciativas. A esse fator juntam-se ainda eventuais represálias que os/as participantes nessas atividades poderão enfrentar por causa da sua participação nestas atividades:

Eu vejo que nos primeiros anos eu tinha colegas que hostilizavam os alunos e prejudicavam-nos nas classificações por causa da participação deles nas atividades. 0 que é que interessa que um aluno falte a duas ou três aulas? Ele pode desenvolver competências que lhe permitem estudar sozinho e se não perceber determinada coisa, pega e vai ao professor. Não é? Porque os alunos que participam nestas atividades desenvolvem um sentido de autonomia e de espírito crítico muito maior. (Elsa, História, escola\#2).

$\mathrm{Na}$ opinião dessa professora, essas atividades assumem uma importância ainda maior no processo educativo dos/as estudantes já que o atual modelo educativo continua, ao nível curricular, a ser demasiado teórico e a incluir poucos espaços para a reflexão dos/ as alunos/as sobre as temáticas que vão sendo abordadas ao longo das aulas. Segundo a mesma professora, a necessária mudança de paradigma educativo passa também pelos/as próprios/as professores/as que, muitas vezes, resistem à mesma por não lhes serem dadas as condições necessárias para que a implementem nas suas práticas pedagógicas:

Talvez as aulas sejam demasiado teóricas, talvez pudessem ser mais práticas... Mas isso exigia que o modelo de ensino não fosse tão hierarquizado, que eles fossem convidados a refletir mais e não fosse só o modelo mais tradicional, mais disciplinar. Esta organização curricular também não facilita muito e os professores estão habituados a um modelo vertical e não abdicam muito dele porque também muitas vezes estão sobrecarregados com turmas. Quem tem 8 turmas enlouquece se estiver sempre a pensar em fazer isto e aquilo nas turmas e, portanto, optam por um modelo mais cómodo. (Elsa, História, escola\#2).

\section{Considerações finais}

Os discursos dos/as professores/as entrevistados/as parecem indicar que as quatro escolas em que estão inseridos/as têm feito um esforço no sentido de preencherem as lacunas observadas nos manuais de História A e de ILE no que se refere à falta de sugestões de atividades que procurem promover a reflexão crítica dos/as estudantes sobre a UE. De fato, alguns desses discursos demonstram que boa parte dos/s participantes neste estudo têm estratégias e práticas pedagógicas que procuram estimular um posicionamento crítico dos/as estudantes relativamente ao futuro da UE, procurando, simultaneamente, contrariar a forma acrítica e normativa como os manuais portugueses 
anteriormente referidos apresentam a cidadania europeia aos estudantes (PIEDADE et al., 2018). Os discursos desses/as professores/as permitiram perceber que, na sua opinião, esse esforço tem sido feito através da dinamização tanto de práticas co-curriculares como de iniciativas extracurriculares, muitas vezes desenvolvidas em parceria com instituições e associações externas que ajudam as escolas a promover a participação cívica e política dos/as estudantes dentro e fora do espaço escolar (RIBEIRO, 2017).

Entre as atividades co-curriculares identificadas encontram-se, desde logo, a realização de debates e o desenvolvimento de projetos sobre temas europeus nas aulas. Foram ainda identificadas outras iniciativas tais como apresentações, feitas por estudantes do ensino superior de outros países europeus a fazerem períodos letivos Erasmus em Portugal, nas aulas de várias disciplinas do ensino secundário. Finalmente, a realização de debates isolados ou de ciclos de debates fora das aulas foi igualmente descrita por alguns professores/as, tanto do ensino regular como do ensino profissional. Embora esse tipo de atividades tenha, efetivamente, potencial pedagógico para estimular a análise crítica dos temas abordados pelos/as participantes e a vantagem de poder abranger a generalidade dos/ as alunos/as do ensino secundário, o seu desenvolvimento tem a limitação de depender, em boa medida, do perfil e disponibilidade do/a professor/a. A maior parte dos/as professores/ as do ensino regular denunciou a falta de tempo, provocada pela extensão excessiva dos currículos das disciplinas, para promover essas atividades de forma sistemática nas suas aulas (ainda que os/as professores/as do ensino profissional tenham referido disporem de mais condições para desenvolverem essas atividades, principalmente na disciplina de AI); além disso, o potencial educativo dessas atividades poderá ser significativamente diminuído ou até mesmo eliminado por uma adoção esporádica e discricionária das mesmas. Urge, portanto, dar condições aos professores/as para que realizem esse tipo de atividades de forma mais sistemática nas suas aulas, o que passa, desde logo, por diminuir o peso dos conteúdos curriculares.

Já relativamente às atividades extracurriculares, os/as professores/as participantes identificaram a realização de visitas de estudos a outros países membros da UE e iniciativas tais como o Parlamento dos Jovens, o Parlamento Europeu dos Jovens e o Clube Europeu como atividades que aproximam os/as jovens portugueses/as da diversidade cultural existente dentro da UE e que promovem uma melhoria dos níveis de conhecimento e de reflexividade sobre a mesma entre os/as estudantes do ensino secundário. Contudo, a participação em atividades tais como as visitas de estudos parece ser fortemente influenciada por fatores socioeconômicos, verificando-se que, nas escolas localizadas em contextos socioeconômicos menos favorecidos (escolas \#1 e \#3), o número de relatos acerca da realização desse tipo de atividades é substancialmente inferior ao verificado em escolas inseridas em contextos socioeconômicos mais favorecidos (escolas \#2 e \#4), sendo mesmo inexistentes no caso da escola(\#1) profissional incluída no estudo. Por outro lado, a insistência nesse tipo de visitas evidencia uma esperança, provavelmente excessiva, nos efeitos positivos sobre os estudantes da observação próxima de uma suposta base identitária europeia comum, cuja delimitação geográfica poderá estar a ser confundida, inconscientemente, pelos próprios atores pedagógicos com as principais rotas turísticas europeias dos últimos 40 anos. 
Quanto às restantes atividades identificadas, verifica-se que, segundo os relatos dos/as professores/as entrevistados/as, nenhuma delas se encontra disponível na escola profissional, sendo que as três escolas do ensino regular apresentam experiências de participação, mais ou menos sistemáticas, no programa Parlamento dos Jovens. Finalmente, e tendo em atenção que apenas a escola\#2 permite aos seus alunos/as a participação no Parlamento Europeu dos Jovens e num Clube Europeu, importa sublinhar que, apesar da sua importância na complementaridade dos conteúdos curriculares ministrados e das atividades co-curriculares anteriormente enunciadas, em geral, esse tipo de iniciativas é menos abrangente no que toca ao universo de alunos/as do ensino secundário. Na opinião de alguns dos/as professores/as entrevistados/as, a participação neste tipo de iniciativas é também afetada tanto pelo tempo que as atividades curriculares formais ocupam na vida dos/as estudantes - levando a que esses/as, muitas vezes, não estejam disponíveis para investirem parte do seu tempo livre nestas atividades - como pelo já referido peso da avaliação.

Independentemente da centralidade assumida pela figura do/a professor/a dentro do modelo educativo português, seria importante complementar essa investigação com estudos que incluam relatos de outros agentes educativos, tais como elementos das direções das escolas e de organizações parceiras das escolas na dinamização de atividades extracurriculares, bem como recolhendo também as perspectivas dos/as próprios/as estudantes relativamente ao desenvolvimento e efeitos desse tipo de atividades na sua ligação com a UE e da sua autoidentificação enquanto cidadãos europeus.

As experiências reportadas pelos/as professores/as dessas escolas podem, contudo, indicar tendências pedagógicas comuns e/ou distintas entre essas duas vias de ensino. Como vimos, os/as professores/as do ensino profissional parecem apostar mais em atividades co-curriculares no sentido de aumentarem os conhecimentos e o grau de reflexão e de identificação dos/as seus alunos/as relativamente à UE, enquanto os/as professores/as do ensino regular parecem investir mais na concretização de atividades extracurriculares. Sendo que já referimos alguns dos fatores que podem concorrer para essas preferências, gostaríamos de acentuar o peso que os recursos econômicos (quer do agregado familiar dos/as alunos/as, quer das próprias escolas) podem ter na escolha entre estas duas estratégias pedagógicas.

Com efeito, o objetivo de aproximar a UE dos/as estudantes portugueses pode ser conseguido tanto pela via co-curricular como extracurricular, sendo que a primeira pode implicar atividades menos dispendiosas e socialmente menos discriminatórias, enquanto a segunda pode envolver mais custos para os/as estudantes. Essa flexibilidade demonstra que a criatividade dos vários agentes educativos pode ajudar a contornar alguns obstáculos no caminho para a educação de cidadãos europeus mais ativos/as e empenhados/as no desenvolvimento do projeto europeu. Tal não deve escusar, contudo, os decisores políticos nacionais e europeus de darem o seu melhor para a criação de condições favoráveis (cf. BONAFÉ; RODRIGUEZ RODRIGUEZ, 2010, p. 24) para que tal aconteça nas escolas. 


\section{Referências}

AGUIAR, Denise. 0 direito de aprender no cotidiano da escola pública. e-Curriculum, São Paulo, v. 15, n. 4, p. 1081-1099, 2017.

BARTKUS, Kenneth et al. Clarifying the meaning of extracurricular activity: a literature review of definitions. American Journal Of Business Education, Littleton, v. 5, n. 6, p. 693-704, 2012.

BEANE, James. Affect in the curriculum: toward democracy, dignity, and diversity. New York: Teachers College Press, 1990.

BEANE, James. Ensinar em prol da democracia. e-Curriculum, São Paulo, v. 15, n. 4, p.1050-1080, 2017.

BIESTA, Gert. Learning democracy in school and society: education, lifelong learning, and the politics of citizenship. Rotterdam: Sense, 2011.

BONAFÉ, Jaume; RODRIGUEZ RODRIGUEZ, Jesús. El curriculum y el libro de texto: una dialéctica siempre abierta. In: SACRISTAN, Gimeno (coord.). Saberes e incertidumbres sobre el curriculum. Madrid: Morata, 2010. p. 246-268.

CAETANO, Andreia et al. Construindo cidadania europeia: impactos de uma intervenção com jovens em escolas portuguesas. Revista Educação Sociedade e Culturas, Porto, v. 49, p. 11-30, 2016.

CHIARO, Sylvia de; AQUINO, Kátia. Argumentação na sala de aula e seu potencial metacognitivo como caminho para um enfoque CTS no ensino de química: uma proposta analítica. Educação e Pesquisa, São Paulo, v. 43, n. 2, p. 411-426, 2017.

CHRYSSOCHOOU, Dimitris. Civic competence and identity in the European polity. In: BELLAMY, Richard; CASTIGLIONE, Dario; SHAW, Jo (ed.). Making European citizens Civic inclusion in a transnational context. New York: Palgrave MacMillan, 2006. p. 219-237.

FERREIRA, Pedro; AZEVEDO, Cristina; MENEZES, Isabel. The developmental quality of participation experiences: beyond the rhetoric that "participation is always good!". Journal of Adolescence, [S. I.], v. 35, n. 3, p. 599-610, 2012. Disponível em: https://www.sciencedirect.com/science/article/abs/pii/ S0140197111001217?via\%3Dihub. Acesso em: 06 abr. 2021.

FONSECA, Eduardo. Nos interstícios da cidadania: a inevitabilidade e urgência da dimensão da virtude cívica na educação. Educação e Pesquisa, São Paulo, v. 40, n. 1, p. 181-196, 2014.

FREDRICKS, Jennifer; ECCLES, Jacquelynne. Developmental benefits of extracurricular involvement: do peer characteristics mediate the link between activities and youth outcomes? Journal of Youth and Adolescence, [S. I.], v. 34, n. 6, p. 507-520, 2005. https://doi.org/10.1007/s10964-005-8933-5.

FREDRICKS, Jennifer et al. A qualitative exploration of adolescents' commitment to athletics and the arts. Journal of Adolescent Research, [S. I.], v. 17, n. 1, p. 68-97, 2002. https://doi. org/10.1177/0743558402171004 
FREIRE, Paulo. Pedagogy of the oppressed: 30th anniversary edition. New York; London: Continuum International Publishing, 2000.

GIROUX, Henry. Pedagogia crítica, Paulo Freire, e a coragem para ser político. e-Curriculum, São Paulo, v. 14, n. 1, p. 296-306, 2016.

HERMANN, Christoph. Neoliberalism in the European Union. Studies in Political Economy, Ottawa, v. 79 , n. 1, p. 61-90, 2007.

JOFFE, Héléne; YARDLEY, Lucy. Content and thematic analysis. In: MARKS, David; YARDLEY, Lucy. Research methods for clinical and health psychology. London: Sage, 2004. p. 56-68.

KARIYANA, Israel; MAPHOSA, Cosmas; MAPURANGA, Beginner. The influence of learners' participation in school co-curricular activities on academic performance: assessment of educators' perceptions. Journal of Social Sciences, New Delhi, v. 33, n. 2, p. 137-146, 2012.

KEATING, Avril. Education for citizenship in Europe: European policies, national adaptations and young people's attitudes. Hampshire: Palgrave Macmillan, 2014.

KEATING, Avril; JANMAAT, Jan. Education through citizenship at school: do school activities have a lasting impact on youth political engagement? Parliamentary Affairs, Oxford, v. 69, n. 2, p. 409-429, 2016.

KESER, Filiz; AKAR, Hanife; YILDIRIM, Ali. Role of extracurricular activities in active citizenship education. Journal of Curriculum Studies, [S. I.], v. 43, n. 6, p. 809-837, 2011. https://doi.org/10.1080/0022027 2.2011 .591433

LAWSON, Helen. Active citizenship in schools and the community. The Curriculum Journal, [S. I.], v. 12, n. 2, p. 163-178, 2001. https://doi.org/10.1080/09585170122413.

MARZANA, Daniela; MARTA, Elena; POZZI, Maura. Social action in young adults: voluntary and political engagement. Journal of Adolescence, [S. I.], v. 35, n. 3, p. 497-507, 2012. https://doi.org/10.1016/j. adolescence.2011.08.013

MEHM00D, Tahir et al. Impact of co-curricular activities on personality development of secondary school students. International Journal of Humanities and Social Science, New York, v. 2, n. 18, p. 139-145, 2012.

MENDES Fernando. As (novas) práticas dos professores a partir da reorganização curricular. 2013. 256 f. Tese (Doutorado em Educação) - Universidade Portucalense, Porto, 2013. Disponível em: http://hdl. handle.net/11328/689. Acesso em: 06 abr. 2021.

MITCHELL, Katharyne. Neoliberal governmentality in the European Union: education, training, and technologies of citizenship. Environment and Planning D, [S. I.], v. 24, p. 389-407, 2006. https://doi. org/10.1068\%2Fd1804.

NORRIS, Pippa. Democratic phoenix: reinventing political activism. Cambridge: Cambridge University Press, 2002. 
NÓVOA, António; LAWN, Martin (ed.). Fabricating Europe: the formation of the education space. Dordrecht: Kluwer, 2002.

PACHECO, José; PEREIRA, Nancy. Globalização e identidade no contexto da escola e do currículo. Cadernos de Pesquisa, São Paulo, v. 37, n. 131, p. 371-398, 2007.

PARLAMENTO EUROPEU. Report on learning EU at school (Motion for a European Parliament resolution). Bruxelas: Committee on Culture and Education, 2016. Disponível em: https://www.europarl.europa.eu/ doceo/document/A-8-2016-0021_EN.pdf. Acesso em: 06 abr. 2021.

PIEDADE, Filipe et al. As visões dos/as professores/as sobre o ensino da União Europeia e da cidadania ativa. In: MENEZES, Isabel. Reinventar a cidadania europeia dos jovens: as escolas como espaços de educação política. Porto, 2020. p. 25-43. No prelo.

PIEDADE, Filipe et al. Learning about the European Union in times of crisis: Portuguese textbooks' normative visions of European citizenship. Journal of Social Science Education, Bielefeld, v. 17, n. 2, p. 26-33, 2018.

REZENDE, Valéria; SILVA, Maria; DE LELIS, Úrsula. Currículo, conhecimento e poder: desafios contemporâneos para as reformas curriculares e o trabalho docente. e-Curriculum, São Paulo, v. 12, n. 1, p. 991-1011, 2014.

RIBEIR0, Ana Bela. Políticas e práticas de educação para a cidadania na Europa: entre as potencialidades das parcerias com ONG e os riscos de ONGização das políticas educativas. 2017. 333 f. Tese (Doutoramento em Ciências da Educação) - Universidade do Porto, Porto, 2017.

RYBA, Raymond. Developing the European dimension in education: the roles of the European Union and the Council of Europe. In: SWING, Elizabeth; SCHRIWER, Jürgen; ORIVEL, François (ed.). Problems and prospects in European education. London: Praeger, 2000. p. 244-261.

SAVVIDES, Nicola. The European dimension in education: exploring pupils' perceptions at three European schools. Journal of Research on International Education, [S. I.], v. 7, n. 3, p. 304-326, 2008.

SCHIABEL, Daniela; FELICIO, Maria dos Santos. (Re)construção do currículo em ação: elementos propiciadores e cerceadores da autonomia do professor. e-Curriculum, São Paulo, v. 16, n. 3, p. 831-856, 2018.

SEIDMAN, Irving. Interviewing as qualitative research: a guide for researchers in education and the social sciences. New York: Teachers College Press, 2006.

Recebido em: 25.10.19

Revisado em: 02.06.20

Aprovado em: 30.06 .20

Filipe Piedade é doutorando em ciências da educação. Bolsista do Centro de Investigação e Intervenção Educativas (CIIE) e investigador do Instituto de História Contemporânea da Faculdade de Ciências Sociais e Humanas da Universidade Nova de Lisboa (IHC-FCSH). A sua 
investigação é financiada pela Fundação para a Ciência e a Tecnologia (FCT), por meio da bolsa de doutorado (BD/123619/2016).

Norberto Ribeiro é doutor em ciências da educação pela Faculdade de Psicologia e de Ciências da Educação da Universidade do Porto (FPCEUP) e membro integrado do CIIE. Faz pós-doutorado no CIIE, financiado por uma bolsa da FCT (SFRH/BPD/112289/2015).

Carla Malafaia é doutora em ciências da Educação pela FPCEUP, membro integrado do Centro de Investigação e Intervenção Educativas (CIIE-UP) e do Centre for Sociology of Democracy (CSD-Helsínquia).

Manuel Loff é professor na Faculdade de Letras da Universidade do Porto e investigador do IHC-FCSH (coordenador da linha histórias conectadas: construção do Estado, movimentos sociais e economia política) e do Centre d'Estudis sobre Dictadures i Democràcias (CEDID, UAB). Doutor em história e civilização pelo Instituto Universitário Europeu (Florença).

Isabel Menezes é professora catedrática na FPCEUP e membro integrado do CIIE. Tem coordenado investigação sobre educação para a cidadania e participação cívica e política de crianças, jovens e adultos, com especial interesse por grupos discriminados.

Tiago Neves é professor na FPCEUP e membro integrado do CIIE. Os seus interesses de investigação concentram-se na área das desigualdades sociais e educativas, que estuda por meio de métodos qualitativos e quantitativos. 